\title{
BIOmarkers: The Oral History of Organic Geochemistry
}

FATIMA HUSAIN, S.M., ANGEL MOJARRO, JULIANA K DROZD AND ROGER E SUMMONS

Massachusetts Institute of Technology

Presenting Author: fhusain@mit.edu

Capturing and sharing the oral history of organic geochemistry enables early-career and established researchers alike to benefit from the insights of those who came before them. BIOmarkers, an audio series established in 2020, curates interviews with multiple generations of organic geochemists and their collaborators with the goal of archiving the history of the discipline - and the stories that are often left out of published literature - in an open access, digitally-permanent form. Each episode heavily features direct quotes from the scientists interviewed and is shared with the organic geochemistry community using social media and traditional electronic communication methods. The eight-episode first season of BIOmarkers had over 1000 listens, which suggests such discipline-specific audio series are in demand and capable of reaching a committed audience. In this case study, the authors share the design and methods used to produce BIOmarkers, which may be adopted to archive the histories of other emerging geochemical disciplines. 